(C) The Authors 2018. This is an Open Access article, distributed under the terms of the Creative Commons Attribution licence (http:// creativecommons.org/licenses/by/4.0/), which permits unrestricted reuse, distribution, and reproduction in any medium, provided the original work is properly cited.

\title{
Timeline of changes in adaptive physiological responses, at the level of energy expenditure, with progressive weight loss
}

\author{
Siren Nymo ${ }^{1,2 *}$, Silvia R. Coutinho ${ }^{1}$, Linn-Christin H. Torgersen ${ }^{1}$, Ola J. Bomo ${ }^{1}$, Ingrid Haugvaldstad ${ }^{1}$, \\ Helen Truby ${ }^{3}$, Bård Kulseng ${ }^{1,2}$ and Catia Martins ${ }^{1,2}$ \\ ${ }^{1}$ Obesity Research Group, Department of Clinical and Molecular Medicine, Faculty of Medicine, Norwegian University \\ of Science and Technology, Prinsesse Kristinas veg 5, 7030 Trondheim, Norway \\ ${ }^{2}$ Centre for Obesity and Innovation (ObeCe), Clinic of Surgery, St. Olav University Hospital, Prinsesse Kristinas veg 5 , 7030 \\ Trondheim, Norway \\ ${ }^{3}$ Department of Nutrition, Dietetics \& Food, Monash University, Melbourne, 264 Ferntree Gully Road, Notting Hill, VIC 3168, \\ Australia
}

(Submitted 27 September 2017 - Final revision received 28 February 2018 - Accepted 9 March 2018 - First published online 7 May 2018)

\section{Abstract}

Diet-induced weight loss (WL) is associated with reduced resting and non-resting energy expenditure (EE), driven not only by changes in body composition but also potentially by adaptive thermogenesis (AT). When exactly this happens, during progressive WL, remains unknown. The aim of this study was to determine the timeline of changes in RMR and exercise-induced EE (EIEE), stemming from changes in body composition $v$. the presence of AT, during WL with a very-low-energy diet (VLED). In all, thirty-one adults (eighteen men) with obesity (BMI: 37 (SEM 4.5$) \mathrm{kg} / \mathrm{m}^{2}$; age: 43 (SEM 10) years) underwent 8 weeks of a VLED, followed by 4 weeks of weight maintenance. Body weight and composition, RMR, net EIEE (10, 25 and $50 \mathrm{~W}$ ) and AT (for RMR ( $\mathrm{AT}_{\mathrm{RMR}}$ ) and EIEE ( $\mathrm{AT}_{\mathrm{EIEE}}$ )) were measured at baseline, day 3 (2 (sEM 1)\% WL), after 5 and $10 \%$ WL and at weeks 9 (16 (SEM 2) \%) and 13 (16 (SEM 1)\%). RMR and fat mass were significantly reduced for the first time at $5 \%$ WL (12 (sem 8) d) $(P<0.01$ and $P<0.001$, respectively) and EIEE at $10 \%$ WL (32 (sEM 8) d), for all levels of power $(P<0.05)$, and sustained up to week 13. $\mathrm{AT}_{\mathrm{RMR}}$ was transiently present at $10 \% \mathrm{WL}(-460(\operatorname{sem} 690) \mathrm{kJ} / \mathrm{d}, P<0 \cdot 01)$. A fall in RMR should be anticipated at $\geq 5 \% \mathrm{WL}$ and a reduction in EIEE at $\geq 10 \% \mathrm{WL}$. Transient $\mathrm{AT}_{\mathrm{RMR}}$ can be expected at $10 \% \mathrm{WL}$. These physiological adaptations may make progressive WL difficult and will probably contribute to relapse.

\section{Key words: Adaptive thermogenesis: RMR: Exercise-induced energy expenditure}

Obesity, owing to its high prevalence, associated co-morbidities and large socio-economic $\operatorname{costs}^{(1)}$, is probably one of the largest public health problems of the 21st century. Even though a modest weight loss (WL) of $5-10 \%$ is sufficient to induce health benefits ${ }^{(2)}$ and can be achieved in the short term (3-6 months), 80\% will experience relapse, with weight regain apparent after 6-12 months ${ }^{(3,4)}$, making WL maintenance a substantial unresolved issue.

The reduced obese state is associated with increased appetite $^{(5-7)}$ that fuels the desire to consume more energy, despite an overall reduction in total energy expenditure (EE), attributable to a reduction in both resting and non-resting $\mathrm{EE}$, mainly driven by the loss of metabolic active tissue ${ }^{(8,9)}$. The reduction in nonresting EE seen with WL seems to be accounted for mainly by a reduction in exercise-induced $\mathrm{EE}$ (EIEE) ${ }^{(8,9)}$, probably owing to increased efficiency ${ }^{(10)}$, given that physical activity (PA) levels have been shown to increase or not to change with sustained $\mathrm{WL}^{(11,12)}$. Increased skeletal muscle work efficiency means that less energy is used to perform the same volume of exercise ${ }^{(10)}$.
Moreover, some $\mathrm{s}^{(8,10,13,14)}$, but not all, studies ${ }^{(15,16)}$ report a reduction in total $\mathrm{EE}$ and its components (resting and non-resting EE) in excess of what would be predicted, given the measured alterations in fat mass (FM) and fat-free mass (FFM), a mechanism known as adaptive thermogenesis (AT). Therefore, AT can account for a small proportion on the reduction in EE seen with WL. The extent to which these different, but inter-related, physiological mechanisms are important remains controversial. However, combined, these mechanisms may act to reduce WL rate and increase the risk of weight re-gain ${ }^{(7)}$.

AT, which is induced by conditions of negative energy balance, has been shown to be under the influence of several hormones and the sympathetic nervous system. Thyroid hormones, insulin and leptin, as well as sympathetic activity, are likely to be involved in the greater than predicted reduction in both resting and non-resting EE observed with $\mathrm{WL}^{(17)}$. At a cellular level, mitochondrial adenosine triphosphate synthesis efficiency and uncoupling proteins are likely to be involved ${ }^{(17,18)}$.

Abbreviations: AT, adaptive thermogenesis; EE, energy expenditure; EIEE, exercise-induced energy expenditure; FM, fat mass; FFM, fat-free mass; PA, physical activity; VLED, very-low-energy diet; Wk9, week 9; Wk13, week 13; WL, weight loss.

* Corresponding author: S. Nymo, fax +47 72571463, email siren.nymo@ntnu.no 
To our knowledge, no studies have determined the timeline over which EE, both at rest and during exercise, changes with progressive $\mathrm{WL}$ in the obese population. A minimal, but significant, WL (1-2 kg) has been shown to reduce RMR, even below predicted values (AT) in some studies ${ }^{(13)}$, whereas others report no change ${ }^{(19)}$. A reduction in EIEE has been reported after $5 \%$ and $10 \% \mathrm{WL}(10-13 \mathrm{~kg})^{(10,20,21)}$, in some cases below predicted values (AT) ${ }^{(21)}$, whereas others have reported no change even after a $19 \% \mathrm{WL}^{(22)}$. The results are clearly controversial and more research is needed. Moreover, the greater FFM content of WL during energy restriction in men, compared with women ${ }^{(23)}$, may suggest that the changes in EE variables with progressive WL are modulated by sex. Therefore, the primary aim of this study was to determine the timeline over which changes in EE variables (RMR, EIEE and AT) occur during progressive WL with a very-low-energy diet (VLED). A secondary aim was to assess whether this timeline was modulated by sex.

\section{Methods}

\section{Participants}

Healthy adults (18-65 years of age) with obesity $(30 \leq$ BMI $<45 \mathrm{~kg} / \mathrm{m}^{2}$ ) were recruited from the local community by means of newspaper and internet advertising. This study nests within a large WL intervention ( $n$ 100), where individuals with obesity undertook 8 weeks of a VLED and were followed up to 1 year.

Inclusion criteria were as follows: weight stability $(<2 \mathrm{~kg}$ change over the last 3 months), not dieting to lose weight and an inactive lifestyle (defined as $<150 \mathrm{~min}$ of PA of at least moderate intensity ${ }^{(24)}$, which was corroborated via data from the SenseWare activity data collected at baseline; see more details below). Owing to the known effect of phase of menstrual cycle on $\mathrm{RMR}^{(25)}$, women had to be post-menopausal or taking hormonal contraceptives. Exclusion criteria were pregnancy, breast-feeding, clinical significant illness, including diabetes, previous WL surgery and medication known to affect appetite/metabolism or induce WL.

\section{Ethical statement}

The study was approved by the regional ethical committee (reference 2012/1901), registered in ClinicalTrial.gov (NCT01834859) and conducted according to the Declaration of Helsinki, with all participants providing informed written consent.

\section{Study design}

This was a clinical intervention study with repeated measurements. All participants underwent a supervised VLED for 8 weeks, followed by 4 weeks of weight stabilisation, and were asked not to change their PA levels throughout the study (see Fig. 1).

\section{Weight-loss phase}

Participants followed for 8 weeks a VLED (Allévo; Karo Pharma AS) with $2 \cdot 3 / 2 \cdot 8 \mathrm{MJ} / \mathrm{d}$, for women and men, respectively (carbohydrates $42 \%$, protein $36 \%$, fat $18 \%$ and fibre $4 \%$ ), as well as no-energy fluids and low-starch vegetables $(\max 100 \mathrm{~g} / \mathrm{d})$.

\section{Weight stabilisation phase}

At week 9 (Wk9), participants were gradually introduced to normal food, and an individual diet plan was prescribed by a trained dietitian based on estimated energy requirements (measured RMR $\times$ PAL (from individual SenseWear data at week 8)), with 15-20\% energy provided by protein, $20-30$ by $\mathrm{E}$ $\%$ fat and 50-60 E\% by carbohydrates, tailored to achieve weight stabilisation $^{(26)}$.

\section{Objective measures of compliance}

Diet. Participants received a weekly follow-up face-to-face consultation with a dietitian, which included measuring body weight, review of daily food records and monitoring of side effects. Urine acetoacetic acid concentration was measured weekly, using Ketostix reagent strips ${ }^{\circledR}$. Negative ketones $(<0.5 \mathrm{mmol} / \mathrm{l})$ more than once were the reasons for exclusion from the analysis.

Physical activity. Armbands (BodyMedia ${ }^{\circledR}$; SenseWare) were used for $7 \mathrm{~d}$ at baseline, and at weeks 4,8 and 12. The data were considered valid if the participants wore the device for $\geq 4 \mathrm{~d}$, including at least 1 weekend day, $>95 \%$ of the time ${ }^{(27)}$. The following variables were analysed: average metabolic equivalent

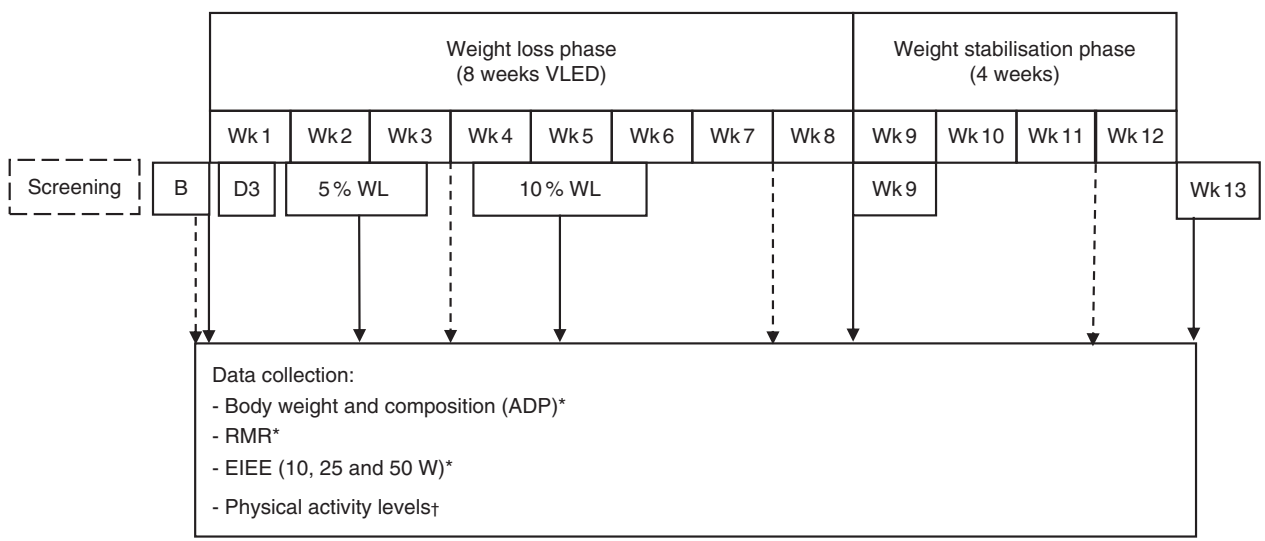

Fig. 1. Study diagram. For data collection points, see arrows. Wk, weeks; VLED, very-low-energy diet; ADP, air-displacement plethysmography; EIEE, exerciseinduced energy expenditure. * $\longrightarrow ; \dagger---\rightarrow$. 
of task (MET), time spent on sedentary, light, moderate and vigorous activities, total PA duration and steps/d.

\section{Data collection}

The following measurements were conducted at baseline, day 3, when each individual participant reached 5 and $10 \% \mathrm{WL}$, and at week 9 (the day immediately after the end of the VLED) and week 13 (Wk13).

Body weight and body composition. Air-displacement plethysmography (ADP) (BodPod; COSMED) was used while participants were in fasting state and in accordance with standard operating procedures.

$R M R$. RMR was measured in fasting state by indirect calorimetry ( $V_{\max }$ Encore $29 \mathrm{~N}$; CareFusion) using a canopy system and following standard procedures ${ }^{(28)}$. Participants were asked to fast for $12 \mathrm{~h}$, not to drink caffeine for at least $6 \mathrm{~h}$, be nicotine abstinent over the last $2 \mathrm{~h}$ and not to perform moderate-intensity PA for $2 \mathrm{~h}$ before test. Although calibration of the equipment was performed, the participants rested for $10 \mathrm{~min}$ on a chair. Thereafter, a ventilation hood was placed over the person's head, and $\mathrm{VO}_{2}$ and $\mathrm{CO}_{2}$ production $\left(\mathrm{VCO}_{2}\right)$ were measured for 15-20 min (or longer if required) until 'steady state' was reached. The first $5 \mathrm{~min}$ were excluded, and $10 \mathrm{~min}$ of stable data (CV for $\mathrm{VO}_{2}$ and $\mathrm{VCO}_{2}<10 \%$ ) were used ${ }^{(28)}$.

Exercise-induced energy expenditure. EIEE was measured by graded cycle ergometry (Eromedic 839E, GIH; Monark), $3 \mathrm{~h}$ after a standardised meal $(2.5 \mathrm{MJ}: 17 \%$ protein, $35 \%$ fat and $48 \%$ carbohydrates). Participants pedalled at $60 \mathrm{rpm}$ against graded resistance to generate 10,25 and $50 \mathrm{~W}$ of power in sequential 4-min intervals. Gas exchange was measured continuously using a face mask by indirect calorimetry ( $V_{\max }$ Encore $29 \mathrm{~N}$ ), and the average of the last $2 \mathrm{~min}$ at each stage was used for analysis. Net EIEE was calculated by subtracting RMR (kJ/min) from the gross $\operatorname{EIEE}^{(21)}$.

\section{Adaptive thermogenesis}

AT was present when measured EE (RMR or EIEE) was lower than predicted, given the body composition (FM and FFM) measured at each time point.

Regression analysis was performed to develop equations to predict both RMR (RMRp) and net EIEE (EIEEp) at each time point, using body composition (FM and FFM (kg)), sex, age and height as predictors. Equations to predict RMR and net EIEE were derived from a data set of ninety-nine participants (forty-four male, aged 43 (SEM 10) years with a BMI of 36 $(\operatorname{sEM} 4) \mathrm{kg} / \mathrm{m}^{2}$ ), which this study is a part of (the participants included in this study were part of the data set):

$\operatorname{RMRp}(\mathrm{kJ} / \mathrm{d})=975 \cdot 712+(33 \cdot 764 \times \mathrm{FM}(\mathrm{kg}))$

$$
\begin{aligned}
& +(63.604 \times \mathrm{FFM}(\mathrm{kg}))+(731.538 \times \text { sex }) \\
& +(11 \cdot 080 \times \text { age }(\text { years }))-(905.169 \times \text { height }(\mathrm{m})) .
\end{aligned}
$$

$R^{2}=0.78$, SEM $=591 \mathrm{~kJ} / \mathrm{d}$ and $P<0.001$.

Net EIEEp $10 \mathrm{~W}(\mathrm{~kJ} / \mathrm{min})=35 \cdot 141+(0 \cdot 029 \times$ age $($ years $))$

$$
\begin{aligned}
& +(0 \cdot 118 \times \mathrm{FM}(\mathrm{kg})) \\
& +(0 \cdot 185 \times \mathrm{FFM}(\mathrm{kg})) \\
& +(1.651 \times \mathrm{sex}) \\
& -(25 \cdot 691 \times \text { height }(\mathrm{m})) .
\end{aligned}
$$

$R^{2}=0.47 ; \operatorname{SEM}=2 \cdot 10 \mathrm{~kJ} / \mathrm{min}$ and $P<0.001$

Net EIEEp $25 \mathrm{~W}(\mathrm{~kJ} / \mathrm{min})=36 \cdot 595+(0 \cdot 013 \times$ age $($ years $))$

$$
\begin{aligned}
& +(0 \cdot 122 \times \mathrm{FM}(\mathrm{kg})) \\
& +(0 \cdot 168 \times \mathrm{FFM}(\mathrm{kg})) \\
& +(1.399 \times \mathrm{sex}) \\
& -(23.822 \times \text { height }(\mathrm{m})) .
\end{aligned}
$$

$R^{2}=0.45 ; \mathrm{SEM}=2.19 \mathrm{~kJ} / \mathrm{min}$ and $P<0.001$

$$
\begin{aligned}
\text { Net EIEEp } 50 \mathrm{~W}(\mathrm{~kJ} / \mathrm{min})= & 40 \cdot 904+(0 \cdot 029 \times \text { age }(\text { years })) \\
& +(0 \cdot 118 \times \mathrm{FM}(\mathrm{kg})) \\
& +(0 \cdot 155 \times \mathrm{FFM}(\mathrm{kg})) \\
& +(1.663 \times \mathrm{sex}) \\
& -(23 \cdot 008 \times \text { height }(\mathrm{m})) .
\end{aligned}
$$

$R^{2}=0.36 ;$ SEM $=2.41 \mathrm{~kJ} / \mathrm{min}$ and $P<0.001$.

\section{Power calculation}

Sample size estimation was based on expected changes (from baseline) in RMR (day 3: -209 ; $5 \%$ WL: $-419,10 \%$ WL: -544 , Wk9: -670 and Wk13: $-377 \mathrm{~kJ} / \mathrm{d})^{(13,19,29,30)}$ for a repeatedmeasures design. For an SD of $958 \mathrm{~kJ} / \mathrm{d}^{(30)}$, at a power of $80 \%$, a significance level of $5 \%$ and assuming a $30 \%$ correlation between time points, thirty-two participants were needed.

\section{Statistical analysis}

Statistical analysis was performed with SPSS version 22 (SPSS Inc.), and data were presented as means with their standard errors, except for baseline anthropometric data, time to achieve 5 and $10 \% \mathrm{WL}$ and WL (\%) at day 3, Wk9 and Wk13, where means and standard deviations are presented. Statistical significance was set at $P<0 \cdot 05$. Data were analysed using linear mixed-effects models, with restricted maximum-likelihood estimation, including fixed effects for time and sex, and their interaction. Bonferroni correction was used for post-hoc pairwise comparisons. RMR was also adjusted for FM and FFM $\left(\mathrm{RMR}_{\mathrm{adj}}\right)$ and analysis was performed by linear mixed-effects models (LMM). Participants with at least three time points were considered completers and kept in the analysis. The BenjaminiHochberg method, which controls for the false discovery rate $^{(31)}$, was used to adjust for the number of outcome variables.

The presence of AT was tested by paired $t$ tests, comparing measured and predicted variables (RMR and EIEE), and a 
$P<0.003$ was considered significant after correcting for multiple comparisons. Correlation analysis was performed between WL and $\mathrm{AT}_{\mathrm{RMR}}$ and $\mathrm{AT}_{\mathrm{EIEE}}$.

The data sets used and/or analysed during the present study are available from the corresponding author on reasonable request.

\section{Results}

\section{Participants}

A total of thirty-three Caucasian participants started the study and thirty-one (eighteen males) were included in the analysis (one woman withdrew owing to personal reasons and one man owing to not tolerating the VLED). Completers had a BMI of 36.7 (SEM 4.5$) \mathrm{kg} / \mathrm{m}^{2}$ and were 43 (SEM 10) years of age. Women had significantly lower body weight (102.7 (SEM 16.3) v. 124.1 $($ SEM $18 \cdot 1) \mathrm{kg}, \quad P<0.01)$ and FFM $(55.6$ (SEM 9.1) $v .74 .2$ (sEm 11.6) kg $P<0.001$ ) compared with men, but there were no significant differences in BMI between sexes.

\section{Compliance}

Diet. Compliance with the VLED was excellent, with no participant being excluded on the basis of not being ketotic.

Physical activity. No significant changes in any of the PA variables analysed were found ${ }^{(32)}$.

\section{Body weight and composition}

Changes in body weight/composition are reported in Fig. 2. Significant WL $(\mathrm{kg})$ occurred by day $3(P<0.001)$ in all participants and in males (1.9 (SEM 0.9) and $2 \cdot 1$ (SEM 1.1) kg, respectively), which continued until $\mathrm{Wk} 9$ in all participants (18.7 (SEM 4.1) kg, $P<0.001$ ), and then stabilised (19.2 (SEM $3.4) \mathrm{kg}, P<0.001)$. On average, participants achieved $5 \% \mathrm{WL}$ in 12 (SEM 6) d (11 (Sem 5) and 15 (Sem 7) d, for men and women,



Fig. 2. Body weight and composition over time in all participants, men and women, with progressive weight loss. Values are estimated marginal means with their standard errors. Wk9, week 9; Wk13, week 13; WL, weight loss; FM, fat mass; FFM, fat-free mass; $\square$, all participants; $\Delta$, males; $\bigcirc$, females; - , body weight; - - - FFM; ......... FM. Significant differences from baseline in all participants: ${ }^{\star \star *} P<0.001$ for body weight, FFM and FM. respectively, NS) and 10\% WL in 32 (SEM 8) d (28 (SEM 7) and 37 (sem 6) d, for men and women, $P<0 \cdot 01$ ). Men lost significantly more weight than women overall $(12.8$ (SEM 0.4) $v .10 \cdot 0$ (sEM 0.4) kg, $P<0.05$ ).

FM $(\mathrm{kg})$ was significantly reduced by $5 \% \mathrm{WL}$ in all participants, men $(P<0.001$ for both $)$ and women $(P<0.01)$, and continued to decrease with progressive WL, being lower than baseline at all time points from WL $\geq 5 \%$. FM loss at Wk9 (16\% WL) was significant in all groups (12.8 (SEM 0.8), $13 \cdot 2$ (SEM 1.1) and 12.3 (sem 1.2) kg, $P<0.001$ for all). A significant loss of FFM was seen at Wk9 only ( $16 \% \mathrm{WL})$ in all participants and in males $(5.2$ (sem 1.0) and 8.3 (sem 1.4) kg, $P<0.001$ for both) (no significant changes were seen in females at any time point). Women had a significantly lower overall FFM compared with men (51.0 (sEm 1.9) v. 72.1 (sem 1.6$) \mathrm{kg}, P<0 \cdot 001$ ).

\section{$R M R$}

RMR $(\mathrm{kJ} / \mathrm{d})$ was significantly reduced after $5 \% \mathrm{WL}$ in all participants (674 (sem 121) kJ/d, $P<0 \cdot 001$ ), men (770 (sEm 159) kJ/d, $P<0.001)$ and women (574 (SEM 188) $\mathrm{kJ} / \mathrm{d}, P<0.05)$, and further WL did not alter it significantly (see Table 1). RMR was lower than baseline at all time points, except for women at Wk13, where RMR was no longer different from baseline. No significant changes in absolute RMR were seen between Wk9 and Wk13, except in males where an increase was seen $(P<0 \cdot 01)$, even though values at Wk13 were still below baseline $(P<0 \cdot 05)$. RMR was significantly higher in men overall (7046 (SEM 197) v. 5347 (SEM 230) kJ/d, respectively). Adjusted RMR $(\mathrm{kJ} / \mathrm{d})$ was only significantly lower than baseline at 5 and $10 \% \mathrm{WL}$ in all participants $(P<0.01$, for both), and $10 \%$ and Wk9 $(16 \% \mathrm{WL})$ in men $(P<0.01$ and $P<0.05$, respectively). A significant increase in adjusted RMR was seen between Wk9 and Wk13 $(P<0 \cdot 01)$ in men only.

Adjusted RMR was significantly higher in men overall (6703 (SEM 155) v. $5690($ SEM 180) kJ/d, respectively, $P<0 \cdot 001)$.

\section{Net exercise-induced energy expenditure}

Net EIEE at $10 \mathrm{~W}$ was significantly reduced, compared with baseline, after $10 \% \mathrm{WL}$ in all participants $(P<0.01)$ and in males $(P<0.05)$, and remained significantly lower than baseline at Wk9 $(P<0.001$ and $P<0.01$, respectively) and Wk13 $(P<0.001$ for both) (see Table 2). In women, a significant reduction in net EIEE at $10 \mathrm{~W}$ was seen at Wk13 $(P<0 \cdot 01)$. Net EIEE at $25 \mathrm{~W}$ was significantly reduced for the first time at $10 \% \mathrm{WL}$ in all participants $(P<0.01)$, and in men at Wk9 $(P<0.01)$ and continued to be lower afterwards $(P<0.001$, for both all and males). Net EIEE at $50 \mathrm{~W}$ was significantly reduced at $10 \% \mathrm{WL}$ in all participants and in males $(P<0.05$ for both), and remained lower than baseline at Wk9 $(P<0.01$ for both $)$ and Wk13 $(P<0.001$ for both), but no differences between Wk9 and Wk13 were seen for any groups.

\section{Adaptive thermogenesis}

$\mathrm{AT}_{\mathrm{RMR}}$ was only significantly reduced after $10 \% \mathrm{WL}$ for all participants $(-465$ (sem 691) kJ/d, $P<0.01)$ and after $10 \% \mathrm{WL}$ 
Table 1. RMR over time in all participants, men and women

(Mean values with their standard errors)

\begin{tabular}{|c|c|c|c|c|c|c|c|c|c|c|c|c|}
\hline & \multicolumn{2}{|c|}{ Baseline } & \multicolumn{2}{|c|}{ Day 3} & \multicolumn{2}{|c|}{$5 \% \mathrm{WL}$} & \multicolumn{2}{|c|}{$10 \% W L$} & \multicolumn{2}{|c|}{ Wk9 } & \multicolumn{2}{|c|}{ Wk13 } \\
\hline & Mean & SEM & Mean & SEM & Mean & SEM & Mean & SEM & Mean & SEM & Mean & SEM \\
\hline \multicolumn{13}{|c|}{ RMR (MJ/d) } \\
\hline All & $6 \cdot 8$ & 0.2 & $6 \cdot 6$ & 0.2 & $6 \cdot 1^{* * *}$ & 0.2 & $5 \cdot 9^{* * *}$ & 0.2 & $5 \cdot 8^{\star \star *}$ & 0.2 & $6 \cdot 1^{\star \star *}$ & 0.2 \\
\hline Men & $7 \cdot 7$ & 0.2 & $7 \cdot 6$ & 0.2 & $6 \cdot 9^{\star \star \star}$ & 0.2 & $6 \cdot 6^{\star \star *}$ & 0.2 & $6 \cdot 3^{\star \star *}$ & 0.2 & $7 \cdot 1^{*}$ & 0.2 \\
\hline Women & $5 \cdot 8$ & 0.3 & $5 \cdot 6$ & 0.3 & $5 \cdot 2^{*}$ & 0.3 & $5 \cdot 1^{* *}$ & 0.3 & $5 \cdot 2^{*}$ & 0.3 & $5 \cdot 1$ & 0.3 \\
\hline \multicolumn{13}{|c|}{$\mathrm{RMR}_{\mathrm{adj}}(\mathrm{MJ} / \mathrm{d})$} \\
\hline All & $6 \cdot 5$ & 0.1 & $6 \cdot 4$ & 0.1 & $6 \cdot 0^{\star \star}$ & 0.1 & $5 \cdot 9^{\star \star}$ & 0.1 & $6 \cdot 0$ & 0.1 & $6 \cdot 4$ & $0 \cdot 2$ \\
\hline Men & $7 \cdot 0$ & 0.2 & $7 \cdot 0$ & 0.2 & 6.5 & 0.2 & $6 \cdot 3^{\star \star}$ & 0.2 & $6 \cdot 3^{*}$ & 0.2 & $7 \cdot 1$ & 0.2 \\
\hline Women & 5.9 & 0.2 & $5 \cdot 8$ & 0.2 & 5.5 & 0.2 & 5.5 & 0.2 & $5 \cdot 8$ & 0.2 & 5.7 & 0.3 \\
\hline
\end{tabular}

WL, weight loss; Wk9, week 9; Wk13, week 13; RMR ${ }_{\text {adj }}$, RMR adjusted for fat-free mass and fat mass as covariates in LMM.

Significant differences from baseline: ${ }^{*} P<0.05,{ }^{\star \star} P<0.01,{ }^{\star \star \star} P<0.001$.

Table 2. Net exercise-induced energy expenditure (EIEE) over time in all participants, men and women† (Mean values with their standard errors)

\begin{tabular}{|c|c|c|c|c|c|c|c|c|c|c|c|c|}
\hline & \multicolumn{2}{|c|}{ Baseline } & \multicolumn{2}{|c|}{ Day 3} & \multicolumn{2}{|c|}{$5 \% \mathrm{WL}$} & \multicolumn{2}{|c|}{$10 \% W L$} & \multicolumn{2}{|c|}{ Wk9 } & \multicolumn{2}{|c|}{ Wk13 } \\
\hline & Mean & SEM & Mean & SEM & Mean & SEM & Mean & SEM & Mean & SEM & Mean & SEM \\
\hline \multicolumn{13}{|c|}{ Net EIEE $10 \mathrm{~W}(\mathrm{~kJ} / \mathrm{min})$} \\
\hline All & 11.93 & 0.50 & $11 \cdot 30$ & 0.50 & 10.93 & 0.50 & $10 \cdot 47^{* *}$ & 0.50 & $10 \cdot 22^{\star \star \star}$ & 0.50 & $9 \cdot 21^{\star \star \star}$ & 0.54 \\
\hline Men & 12.48 & 0.63 & 11.68 & 0.63 & 11.47 & 0.63 & $10 \cdot 97^{\star}$ & 0.67 & $10 \cdot 38^{\star \star}$ & 0.67 & $9 \cdot 67^{\star \star \star}$ & 0.71 \\
\hline Women & 11.35 & 0.75 & $10 \cdot 89$ & 0.75 & $10 \cdot 34$ & 0.75 & $10 \cdot 01$ & 0.75 & 10.01 & 0.75 & $8 \cdot 71^{\star *}$ & 0.88 \\
\hline \multicolumn{13}{|c|}{ Net EIEE 25 W (kJ/min) } \\
\hline All & 14.82 & 0.54 & 14.03 & 0.54 & 13.82 & 0.54 & $13 \cdot 36^{* *}$ & 0.54 & $13 \cdot 10^{\star *}$ & 0.54 & $12 \cdot 31^{\star \star *}$ & 0.59 \\
\hline Men & 15.41 & 0.67 & 14.44 & 0.64 & 14.49 & 0.67 & 13.86 & 0.67 & $13 \cdot 40^{\star \star}$ & 0.71 & $12 \cdot 73^{\star * *}$ & 0.75 \\
\hline Women & $14 \cdot 24$ & 0.80 & $13 \cdot 61$ & 0.80 & 13.60 & 0.80 & 12.90 & 0.80 & $12 \cdot 81$ & 0.80 & 11.93 & 0.96 \\
\hline \multicolumn{13}{|c|}{ Net EIEE $50 \mathrm{~W}(\mathrm{~kJ} / \mathrm{min})$} \\
\hline All & $20 \cdot 22$ & 0.54 & 19.68 & 0.54 & 19.85 & 0.54 & $18 \cdot 71^{*}$ & 0.54 & $18 \cdot 51^{\star \star}$ & 0.54 & $17 \cdot 50^{\star \star \star}$ & 0.59 \\
\hline Men & $20 \cdot 72$ & 0.67 & $20 \cdot 10$ & 0.71 & 20.47 & 0.67 & $18 \cdot 92^{*}$ & 0.71 & $18 \cdot 55^{\star \star}$ & 0.71 & $17 \cdot 79^{\star \star *}$ & 0.75 \\
\hline Women & $19 \cdot 72$ & 0.84 & 19.22 & 0.84 & 19.05 & 0.80 & $18 \cdot 15$ & 0.80 & 18.51 & 0.84 & $17 \cdot 25$ & 1.00 \\
\hline
\end{tabular}

WL, weight loss; Wk9, week 9; Wk13, week13.

Significant differences from baseline: ${ }^{*} P<0.05$, ${ }^{\star *} P<0.01$, ${ }^{\star \star \star} P<0.001$.

$\dagger$ No differences between time points were seen.

and at Wk9 in men (-716 (SEM 670) and -553 (SEM 582) kJ/d, respectively, $P<0.01$ for both) (See Fig. 3(a)). $\mathrm{AT}_{\mathrm{RMR}}$ was significantly higher in men compared with women at 5 and $10 \% \mathrm{WL}$, and $\mathrm{Wk} 9(P<0.05, P<0.01$ and $P<0.05$, respectively).

A negative correlation was found between magnitude of WL $(\mathrm{kg})$ and $\mathrm{AT}_{\mathrm{RMR}}$ at 5\% WL ( $n$ 30, $r-0.491$ and $P<0 \cdot 01$ ), $10 \%$ WL $(n 29, r-0.391$ and $P<0.05)$ and Wk9 $(n 29, r-0.224$ and $P<0 \cdot 01)$, with a higher WL being associated with a larger $\mathrm{AT}_{\mathrm{RMR}}$ $\left(\mathrm{RMR}_{\mathrm{m}}<\mathrm{RMR}_{\mathrm{p}}\right.$ ) (Fig. 3(b)).

No evidence of $\mathrm{AT}_{\mathrm{EIEE}}$ was found (Fig. 4) and $\mathrm{AT}_{\mathrm{EIEE}}$ was not correlated with WL.

\section{Discussion}

This study is the first to repeatedly measure RMR and EIEE, using a longitudinal design, to explore physiological adaptions to progressive WL. Despite significant WL by day 3 (2 (SEM 1) kg WL), there was no significant drop in RMR, which is in line with previous research ${ }^{(19)}$. Our findings show a significant reduction in RMR (10 ( $\operatorname{sem} 2) \%$ ) by the time $5 \%$ WL $(12$ (SEM 8) d) was reached, with no further reduction up to $16 \% \mathrm{WL}$, which is in agreement with previous research ${ }^{(33)}$. Moreover, we found that the reduction in RMR was sustained even after a period of weight stabilisation, which again is in line with previous studies $^{(8,30)}$

A greater fall in RMR has been reported in studies with a shorter $v$. longer duration $(\leq v .>6 \text { weeks })^{(34)}$, suggesting that the reduction in RMR seen with WL is more pronounced during the 1st week of energy restriction, which supports our findings. When we adjusted RMR for FM and FFM, only a transient reduction was seen at 5 and $10 \%$ WL in all participants and 10 and $16 \%$ in men. This concurs with Ballor et al. ${ }^{(35)}$, who reported a significant reduction in RMR (both absolute and adjusted values) with a $10 \%$ WL induced by diet alone. Contrary to our findings, Leibel et $a l^{(8)}$ reported a reduction in RMR adjusted for FFM at $20 \%$, but not $10 \%$ WL, in a mixed sample of men and women with obesity. Overall, our results show that a $\mathrm{WL} \geq 5 \%$, seen as the minimum required to achieve health benefits $^{(2)}$, already leads to a significant reduction in RMR, but further WL up to $16 \%$ does not induce a further significant decline in RMR.

The fact that we did not detect a significant change in EIEE until the WL was $\geq 10 \%$ (12 (sEm 2) kg) for all levels of power is in line with most of the available evidence ${ }^{(10,20,35)}$. However, Amati et al. ${ }^{(22)}$ did not find any change in gross EIEE (at an 

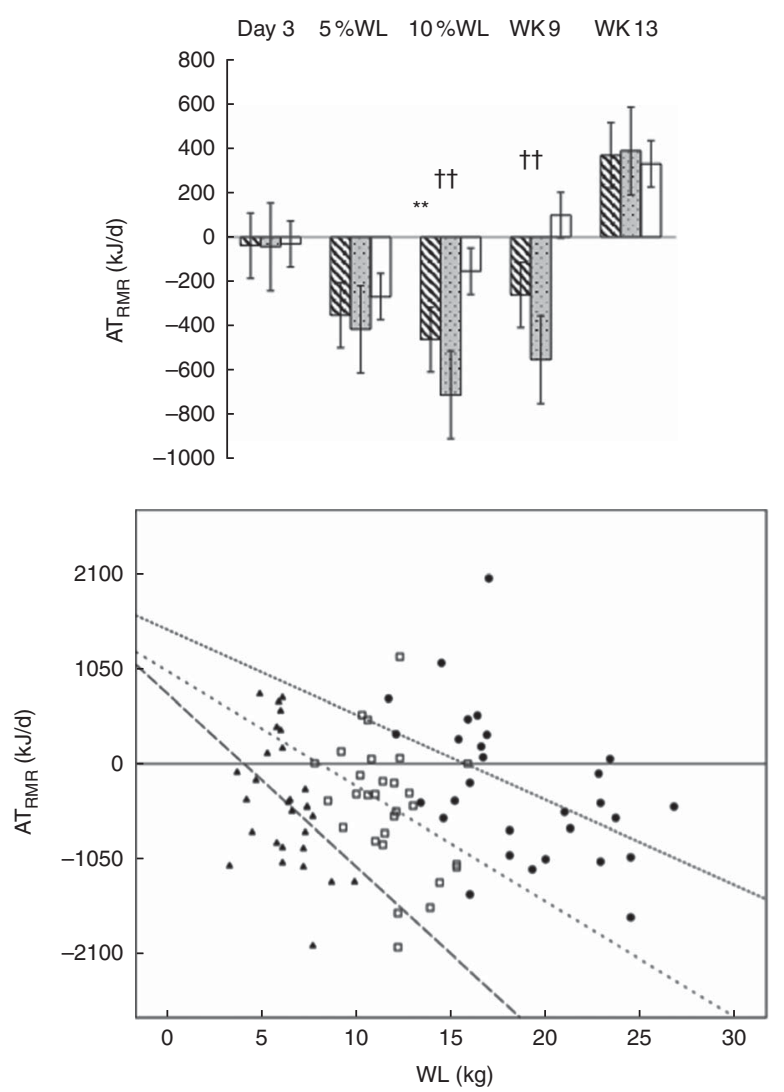

Fig. 3. (a). Adaptive thermogenesis (AT) at the level of RMR with progressive weight loss (WL), in all participants ( $\square)$, men (B) and women $(\square)$. Values are means with their standard errors. Wk9, week 9; Wk13, week 13. $\mathrm{RMR}_{\text {measured }}<\mathrm{RMR}_{\text {predicted: }}{ }^{* *} P<0.01$ for all, $\mathrm{\dagger} P<0.01$ for males. (b). Correlation of $\mathrm{AT}_{\mathrm{RMR}}$ against $\mathrm{WL}$ at $5 \%, 10 \%$ and week 9 in all participants was investigated by using Spearman's $\rho$ correlation coefficient; a larger $\mathrm{AT}_{\mathrm{RMR}}$ was associated with a larger WL. The equation for the regression lines: $5 \%$ WL; $Y=-210 \times X+962, \quad 10 \% \mathrm{WL} ; \quad Y=-126 \times X+1025$, and week 9; $Y=-92 \times X+1483 .-\cdots, \mathrm{AT}_{\mathrm{RMR}} 5 \% \mathrm{WL}, R^{2}=0.241 \quad(P<0.01) ; \cdots \cdots$, $\mathrm{AT}_{\mathrm{RMR}} 10 \%$ WL, $R^{2}=0.153(P<0.05) ; \cdots . . ., \mathrm{AT}_{\mathrm{RMR}} \mathrm{W} 9, R^{2}=0.285$ $(P<0.01)$.

average power $38 \pm 2 \mathrm{~W}$ ) with a $19 \% \mathrm{WL}$ induced by diet alone, followed by 2 weeks of weight stabilisation. Conflicting results may be explained by different protocols used to measure EIEE and the fact that this is sometimes expressed as gross and others as net EIEE.

$\mathrm{AT}_{\mathrm{RMR}}$ was only present at $10 \% \mathrm{WL}$ in all participants and at $10 \% \mathrm{WL}$ and $\mathrm{Wk} 9$ (16\% WL) in men, which is similar to other studies ${ }^{(30,36,37)}$. Rosenbaum \& Leibel ${ }^{(37)}$ reported $\mathrm{AT}_{\mathrm{RMR}}$ after $10 \%$, but not $20 \%$, WL induced by diet alone. Camps et al. ${ }^{(30)}$ also found $\mathrm{AT}_{\mathrm{RMR}}$ with $10 \%$ WL achieved with a VLED, but opposite to us, that was sustained after 12 weeks of follow-up. On the other hand, other studies do not support the existence of $\mathrm{AT}_{\mathrm{RMR}}$ after 5 or $10 \% \mathrm{WL}^{(38,39)}$. Differences in compliance, follow-up and sample size may account for some of these discrepancies. More studies are needed to confirm whether $\mathrm{AT}_{\mathrm{RMR}}$ is indeed a transient phenomenon, and whether women are protected from it. In the present study, a larger $\mathrm{AT}_{\mathrm{RMR}}$ was associated with a larger WL, up to $22 \% \mathrm{WL}$, but not after a period of weight stabilisation. Camps et al. ${ }^{(30)}$ also found a correlation between $\mathrm{AT}_{\mathrm{RMR}}$ and magnitude of $\mathrm{WL}$, up to $25 \%$
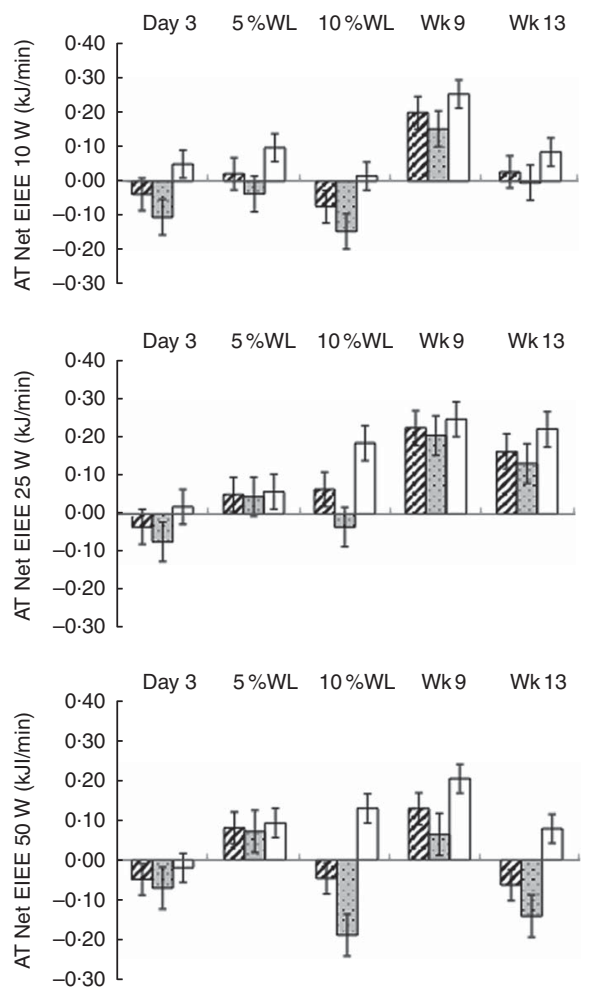

Fig. 4. Adaptive thermogenesis (AT) at the level of net exercise-induced energy expenditure (EIEE) (10, 25 and $50 \mathrm{~W}$ ) with progressive weight loss (WL) in all participants $(\square)$, men $(\square)$ and women $(\square)$. Values are means with their standard errors. Wk9, week 9 ; Wk13, week 13. No significant differences were found between net EIEE measured and predicted at any time point.

WL. In an in-patient, well-controlled study, Muller et al. ${ }^{(40)}$ showed in eight normal-weight men a significant reduction in $\mathrm{RMR}$, and the presence of $\mathrm{AT}_{\mathrm{RMR}}$, after only $3 \mathrm{~d}$ on a $50 \%$ energy-restricted diet (WL, approximately $1.7 \mathrm{~kg}$ ). They also showed a significant reduction in RMR and the presence of $\mathrm{AT}_{\mathrm{RMR}}$ after 1 week (WL, approximately $2 \cdot 2 \mathrm{~kg}$ ) in 32 non-obese men, with no further significant changes with progressive WL up to 3 weeks (WL, approximately $4 \mathrm{~kg}$ ( $5 \% \mathrm{WL}$ )). Inconsistencies in outcomes between this and the present study may be owing to differences in sex distribution (males $v$. mixed sex), participant's characteristics (non-obese $v$. obese), dietary intervention and magnitude of WL. Even though the accuracy of our RMRp was not perfect, it is in line with that seen with WHO equation $^{(41)}$ and we were unable to find any established equation that would result in a better accuracy.

No $\mathrm{AT}_{\mathrm{EIEE}}$ was found at any time point or level of power in the present study. Other studies have reported $\mathrm{AT}_{\mathrm{EIEE}}$ to be present after a WL between 10 and $20 \%$, followed by $2-3$ weeks of weight stabilisation ${ }^{(8,9)}$. Differences in outcomes among studies can probably be explained by diverse sample sizes, participants' characteristics, magnitude of WL, WL intervention and protocols used to measure and predict EIEE (stationary bike $v$. treadmill, different resistances, speeds and inclinations). Moreover, non-resting EE is not the same as EIEE, and thus comparisons between studies need to be done carefully. When adjusting RMR for body composition, and assessing the presence of $\mathrm{AT}_{\mathrm{RMR}}$, it was assumed that the composition of 
FFM was constant during WL. However, FFM hydration probably changed, given that ketogenic diets lead to a large loss of total body water, owing to glycogen depletion, during the 1 st days of the diet ${ }^{(42,43)}$. This might have biased body composition results and affected our outcomes, particularly those taken at day 3. These results need to be interpreted with caution, given that the accuracy of EIEEp was not optimal. However, we are not aware of any established equation that could be used to improve the accuracy of EIEEp.

This study revealed some important sex differences. In women, there was no significant change from baseline in neither absolute nor adjusted RMR, after a $16 \%$ sustained WL. This is in line with Doucet et $a l^{(44)}$, who found a sustained reduction in RMR after an average $10 \%$ WL only in men. On the other hand, Schwartz \& Doucet ${ }^{(34)}$, in a systematic review on the effects of diet-induced WL on RMR, reported a similar decrease in RMR for both sexes. A reduction in net EIEE in women was only seen for $10 \mathrm{~W}$ at Wk13 (16 (SEM 2)\%), which is in line with a previous study ${ }^{(14)}$. Some of the sex differences seen in this study may be attributed to differences in energy and protein deficit, which lead to a larger overall WL in men and might have also contributed to the fact that FFM did not change in women, whereas in men there was a significant reduction at $16 \%$ WL. This is supported by literature, which suggests that FFM reduction during WL is proportionally greater in men ${ }^{(23)}$. $\mathrm{AT}_{\mathrm{RMR}}$ was not seen in women at any time point. This is in line with Doucet et $a l^{(13)}$, who reported $\mathrm{AT}_{\mathrm{RMR}}$ after 8 weeks on a diet in men only ${ }^{(13)}$. On the other hand, Camps et al. ${ }^{(30)}$ reported $\mathrm{AT}_{\mathrm{RMR}}$ in both sexes after a $9.6(\mathrm{SEM} 4 \cdot 1) \mathrm{kg}$ WL induced with a VLED. Leptin has been suggested as a potential mediator to explain the differences in AT between sexes ${ }^{(45)}$. Owing to their relatively higher percentage of FM compared with men, women have a higher leptin plasma concentration, and the reduction seen with WL may translate in leptin plasma concentration falling below a threshold level in men, but not in women ${ }^{(46)}$. Given that $\mathrm{AT}_{\mathrm{RMR}}$ has been shown to be positively correlated with the reduction in leptin seen with $\mathrm{WL}^{(47)}$, it could potentially explain why $\mathrm{AT}_{\mathrm{RMR}}$ was only seen in men in this study.

This study has several strengths. First, its longitudinal design is unique, with multiple measurements undertaken during progressive WL. This allowed us to evaluate the effect of minimal, but significant WL (day 3), WL known to induce health benefits $(5-10 \%)^{(2)}$ and a larger WL (16\%), before and after weight stabilisation, on the different outcome variables. Second, compliance was objectively monitored and was excellent. Third, we adjusted for multiple comparisons and multiple outcome variables. However, this study has also limitations. The fact that body composition was measured by ADP, and as such did not take into account the level of FFM hydration, may have affected the absolute values, particularly regarding adjusted RMR and AT at rest. Moreover, the best regression model to predict EIEE had a relatively modest $R^{2}$, with $<47 \%$ of the variation in EIEE being explained by the model, which could have an impact on our estimation of $\mathrm{AT}_{\mathrm{EIEE}}$. It needs also to be acknowledged that measured baseline RMR values in this study were on average $20 \%$ lower than predicted by the Mifflin equation $^{(48)}$, with $80 \%$ of the participants presenting RMR values below predicted (difference between measured and predicted $>10 \%$ ). This has been previously described. Weijs ${ }^{(49)}$ showed in an adult Dutch population with overweight and obesity (average BMI $30 \mathrm{~kg} / \mathrm{m}^{2}$ ) that $50 \%$ of the individuals had a measured RMR (measured with the same equipment as in the present study) lower than that predicted by the Mifflins equation. The reasons for the lower percentage of individuals with accurate values in the present study compared with Weijs remains speculative, but the fact that our population was substantially more obese (BMI 36.7 (SEM 4.5) v. $30 \cdot 8$ (SEM 3.6) $\mathrm{kg} / \mathrm{m}^{2}$ ), had a body composition with a high \% of nonmetabolically active body fat and also with different genetic background (Norwegian) might all have had an impact. Moreover, our sample comprises individuals with obesity who had sought treatment, and it is possible that at least some of the participants presented with AT as a result of previous weigh loss-regain cycles ${ }^{(17)}$. As the main aim of this study was to look at changes over time, even if RMR values are underestimated compared with a standard predictive equation, the longitudinal nature of the study methods and statistical analysis takes into consideration baseline values, and thus the overall findings of the study are still valid. Finally, the study may be underpowered to examine sex differences.

This study has several practical implications. Patients need to be assured that a WL $>5 \%$, and up to $16 \%$, will not necessarily translate into further significant reductions in their basal energy needs. This knowledge is important for practitioners when reformulating dietary prescriptions for progressive WL and WL maintenance. When aiming for progressive weight reduction after $\geq 10 \% \mathrm{WL}$, a larger dietary energy restriction and/or an increase in PA levels are essential to counteract the decrease in EIEE seen at this time point. A slowdown in WL rate after $\geq 10 \%$ WL can, at least partially, be explained by the transient $\mathrm{AT}_{\mathrm{RMR}}$ seen at this time point. Practitioners need to be aware of these physiological adaptations and not assume that non-compliance with the diet is the sole explanation. Knowing when changes in EE, at rest and during exercise, occur with progressive WL is important to understand resistance with progressive WL and relapse after treatment, and should be discussed alongside patients' expectations of their WL journey.

In conclusion, a fall in RMR should be anticipated at $\geq 5 \% \mathrm{WL}$, a reduction in EIEE at $\geq 10 \%$ WL and transient ATRMR at $10 \%$ WL. These metabolic compensatory responses can make further WL difficult and increase the risk of relapse. Sex seems to modulate some of these responses, but larger long-term longitudinal studies are needed.

\section{Acknowledgements}

The authors thank all participants for their time and commitment, Hege Bjøru and Sissel Salater (ObeCe, Clinic of Surgery, St. Olavs University Hospital) for support with screening and blood collection and Turid Follestad (NTNU) for helping with statistical analysis.

The Liaison Committee for education, research and innovation in Central Norway provided funding. Allévo, Karo Pharma 
Sverige $\mathrm{AB}$ provided the VLED products (no commercial interest).

C. M., B. K., H. T. and S. N. formulated the research questions and designed the study. S.N., S. R. C., L.C. H. T., O. J. B. and I. H. carried out the study, S. N. and S. R. C. analysed the data and all authors were involved in the writing of the article.

The authors declare that there are no conflicts of interest.

\section{References}

1. World Health Organization (2015) Obesity and overweight. http://www.who.int/mediacentre/factsheets/fs311/en/ (accessed October 2016)

2. Blackburn G (1995) Effect of degree of weight loss on health benefits. Obes Res 3, Suppl. 2, 211s-216s.

3. Anderson JW, Konz EC, Frederich RC, et al. (2001) Long-term weight-loss maintenance: a meta-analysis of US studies. $A m \mathrm{~J}$ Clin Nutr 74, 579-584.

4. Kraschnewski JL, Boan J, Esposito J, et al. (2010) Long-term weight loss maintenance in the United States. Int $J$ Obes (Lond) 34, 1644-1654.

5. Cornier MA (2011) Is your brain to blame for weight regain? Physiol Behav 104, 608-612.

6. Doucet E \& Cameron J (2007) Appetite control after weight loss: what is the role of bloodborne peptides? Appl Physiol Nutr Metab 32, 523-532.

7. Maclean PS, Bergouignan A, Cornier MA, et al. (2011) Biology's response to dieting: the impetus for weight regain. Am J Physiol Regul Integr Comp Physiol 301, R581-R600.

8. Leibel RL, Rosenbaum M \& Hirsch J (1995) Changes in energy expenditure resulting from altered body weight. $N$ Engl J Med 332, 621-628.

9. Rosenbaum M, Hirsch J, Gallagher DA, et al. (2008) Long-term persistence of adaptive thermogenesis in subjects who have maintained a reduced body weight. Am J Clin Nutr 88, 906-912.

10. Rosenbaum M, Vandenborne K, Goldsmith R, et al. (2003) Effects of experimental weight perturbation on skeletal muscle work efficiency in human subjects. Am J Physiol Regul Integr Comp Physiol 285, R183-R192.

11. Bonomi AG, Soenen S, Goris AH, et al. (2013) Weight-loss induced changes in physical activity and activity energy expenditure in overweight and obese subjects before and after energy restriction. PLOS ONE 8, e59641.

12. Camps SG, Verhoef SP \& Westerterp KR (2013) Weight loss-induced reduction in physical activity recovers during weight maintenance. Am J Clin Nutr 98, 917-923.

13. Doucet E, St-Pierre S, Almeras N, et al. (2001) Evidence for the existence of adaptive thermogenesis during weight loss. $\mathrm{BrJ}$ Nutr 85, 715-723.

14. Froidevaux F, Schutz Y, Christin L, et al. (1993) Energy expenditure in obese women before and during weight loss, after refeeding, and in the weight-relapse period. Am J Clin Nutr 57, 35-42.

15. Weinsier RL, Hunter GR, Zuckerman PA, et al. (2000) Energy expenditure and free-living physical activity in black and white women: comparison before and after weight loss. $\mathrm{Am} \mathrm{J}$ Clin Nutr 71, 1138-1146.

16. Lazzer S, Boirie Y, Montaurier C, et al. (2004) A weight reduction program preserves fat-free mass but not metabolic rate in obese adolescents. Obes Res 12, 233-240.

17. Major GC, Doucet E, Trayhurn P, et al. (2007) Clinical significance of adaptive thermogenesis. Int $J$ Obes $\mathbf{3 1}$, 204-212.
18. Lowell BB \& Spiegelman BM (2000) Towards a molecular understanding of adaptive thermogenesis. Nature 404, 652-660.

19. Doucet E, Pomerleau M \& Harper ME (2004) Fasting and postprandial total ghrelin remain unchanged after short-term energy restriction. J Clin Endocrinol Metab 89, 1727-1732.

20. Goldsmith R, Joanisse DR, Gallagher D, et al. (2010) Effects of experimental weight perturbation on skeletal muscle work efficiency, fuel utilization, and biochemistry in human subjects. Am J Physiol Regul Integr Comp Physiol 298, R79-R88.

21. Doucet E, Imbeault P, St-Pierre S, et al. (2003) Greater than predicted decrease in energy expenditure during exercise after body weight loss in obese men. Clin Sci (Lond) 105, 89-95.

22. Amati F, Dube JJ, Shay C, et al. (2008) Separate and combined effects of exercise training and weight loss on exercise efficiency and substrate oxidation. J Appl Physiol (1985) 105, $825-831$

23. Millward DJ, Truby H, Fox KR, et al. (2014) Sex differences in the composition of weight gain and loss in overweight and obese adults. Br J Nutr 111, 933-943.

24. Haskell WL, Lee IM, Pate RR, et al. (2007) Physical activity and public health: updated recommendation for adults from the American College of Sports Medicine and the American Heart Association. Med Sci Sports Exerc 39, 1423-1434.

25. Henry CJ, Lightowler HJ \& Marchini J (2003) Intra-individual variation in resting metabolic rate during the menstrual cycle. BrJ Nutr 89, 811-817.

26. Nordic Council of Ministers (2014) Nordic Nutrition Recommendations 2012. Integrating Nutrition and Physical Activity, 5th ed. http://www.norden.org/en/theme/former-themes/ themes-2016/nordic-nutrition-recommendation/nordic-nutritionrecommendations-2012 (accessed April 2018).

27. Scheers T, Philippaerts R \& Lefevre J (2012) Patterns of physical activity and sedentary behavior in normal-weight, overweight and obese adults, as measured with a portable armband device and an electronic diary. Clin Nutr 31, 756-764.

28. Compher C, Frankenfield D, Keim N, et al. (2006) Best practice methods to apply to measurement of resting metabolic rate in adults: a systematic review. J Am Diet Assoc 106, 881-903.

29. Foster GD, Wadden TA, Feurer ID, et al. (1990) Controlled trial of the metabolic effects of a very-low-calorie diet: short- and long-term effects. Am J Clin Nutr 51, 167-172.

30. Camps SG, Verhoef SP \& Westerterp KR (2013) Weight loss, weight maintenance, and adaptive thermogenesis. Am J Clin Nutr 97, 990-994.

31. Benjamini Y \& Hochberg Y (1995) Controlling the false discovery rate: a practical and powerful approach to multiple testing. J R Stat Soc Ser B 57, 289-300.

32. Nymo S, Coutinho SR, Jørgensen J, et al. (2017) Timeline of changes in appetite during weight loss with a ketogenic diet. Int J Obes (Lond) 41, 1224-1231.

33. Kreitzman SN, Coxon AY, Johnson PG, et al. (1992) Dependence of weight loss during very-low-calorie diets on total energy expenditure rather than on resting metabolic rate, which is associated with fat-free mass. Am J Clin Nutr 56, 1 Suppl., 258s-261s.

34. Schwartz A \& Doucet E (2010) Relative changes in resting energy expenditure during weight loss: a systematic review. Obes Rev 11, 531-547.

35. Ballor DL, Harvey-Berino JR, Ades PA, et al. (1996) Decrease in fat oxidation following a meal in weight-reduced individuals: a possible mechanism for weight recidivism. Metabolism 45, 174-178.

36. Rosenbaum M \& Leibel RL (2010) Adaptive thermogenesis in humans. Int J Obes (Lond) 34, Suppl. 1, S47-S55. 
37. Rosenbaum M \& Leibel RL (2016) Models of energy homeostasis in response to maintenance of reduced body weight. Obesity (Silver Spring) 24, 1620-1629.

38. Siervo M, Faber P, Lara J, et al. (2015) Imposed rate and extent of weight loss in obese men and adaptive changes in resting and total energy expenditure. Metabolism 64, 896-904.

39. Schwartz A, Kuk JL, Lamothe G, et al. (2012) Greater than predicted decrease in resting energy expenditure and weight loss: results from a systematic review. Obesity (Silver Spring) 20, 2307-2310.

40. Muller MJ, Enderle J, Pourhassan M, et al. (2015) Metabolic adaptation to caloric restriction and subsequent refeeding: the Minnesota Starvation Experiment revisited. Am J Clin Nutr 102, 807-819.

41. FAO/WHO/UNU (1985) Energy and Protein Requirements. Report of a joint FAO/WHO/UNU Expert Consultation. World Health Organ Tech Rep Ser 724, 1-206.

42. Kreitzman SN, Coxon AY \& Szaz KF (1992) Glycogen storage: illusions of easy weight loss, excessive weight regain, and distortions in estimates of body composition. Am J Clin Nutr 56, 1 Suppl., 292s-293s.

43. Yang MU \& Van Itallie TB (1976) Composition of weight lost during short-term weight reduction. Metabolic responses of obese subjects to starvation and low-calorie ketogenic and nonketogenic diets. J Clin Invest 58, 722-730.

44. Doucet E, St Pierre S, Almeras N, et al. (2000) Changes in energy expenditure and substrate oxidation resulting from weight loss in obese men and women: is there an important contribution of leptin? J Clin Endocrinol Metab 85, 1550-1556.

45. Muller MJ \& Bosy-Westphal A (2013) Adaptive thermogenesis with weight loss in humans. Obesity (Silver Spring) 21, 218-228.

46. Mantzoros CS, Magkos F, Brinkoetter M, et al. (2011) Leptin in human physiology and pathophysiology. Am J Physiol Endocrinol Metab 301, E567-E584.

47. Camps SG, Verhoef SP \& Westerterp KR (2015) Leptin and energy restriction induced adaptation in energy expenditure. Metabolism 64, 1284-1290.

48. Frankenfield D, Roth-Yousey L, Compher C, et al. (2005) Comparison of predictive equations for resting metabolic rate in healthy nonobese and obese adults: a systematic review. J Am Diet Assoc 105, 775-789.

49. Weijs PJ (2008) Validity of predictive equations for resting energy expenditure in US and Dutch overweight and obese class I and II adults aged 18-65 y. Am J Clin Nutr 88, 959-970. 